\title{
A contínua decadência de Portugal nos últimos cem anos
}

Ermelinda Liberato*

COSTA, Jorge et al. Os donos de Portugal (cem anos de poder económico, 1910-2010). Porto: Autores e Edições Afrontamento, 2010.

Rigoroso e conciso são os adjetivos que nos parecem mais adequados para uma primeira classificação de Os donos de Portugal, uma obra inédita que traça o percurso de formação da burguesia portuguesa bem como seu processo de acumulação de capital ao longo dos últimos cem anos. A maturidade analítica e metodológica demonstrada pelos autores consolida a importância desta obra bem como sua validade. Um dos exemplos dessa maturidade reside no cruzamento sutil de diferentes escalas de análise, quer seja macro (quando analisam a história do país), meso (quando analisam a história econômica e política do país) e micro (quando analisam em particular o percurso das famílias burguesas portuguesas). Essas três diferentes escalas de análise dão-nos, assim, um retrato completo da história econômica, política, social e cultural de Portugal ao longo do período de referência.

Recensear um livro com tal teor histórico apresenta-se como uma tarefa complexa, pois o quadro teórico e a informação que este contém não podem ser analisados apenas em partes. $\mathrm{O}$ livro em si é composto por detalhes que se interligam e que constituem um todo. Uma vasta pesquisa assente numa extensa bibliografia que inclui revista de imprensa, obras bibliográficas e artigos acadêmicos que permitiram uma exausti- va sistematização de informação, dá suporte aos seis capítulos que constituem a obra e nos quais os autores desvelam a "natureza da evolução secular da economia portuguesa e das suas crises, sobre o atraso ou a dependência, sobre a industrialização e o comércio externo, sobre o papel do salazarismo e do seu Estado Novo, sobre o afundamento da agricultura e o fracasso dos projetos de reforma agrária” (p. 13). Partindo desse pressuposto, os autores procuram analisar como se processou a constituição da burguesia portuguesa, como se relacionou nos meios em que se movimentava (nacional e internacional), suas relaçóes com os diferentes regimes políticos instituídos e como se vem reconstituindo ao longo dos últimos cem anos.

Cada um dos capítulos da obra aborda um período específico de evoluçáo e crescimento da burguesia, assim como a intensificação das relaçóes entre esta e o poder político. Essa burguesia caracteriza-se por uma teia de relaçóes próximas em que um grupo restrito de famílias se cruza numa mesma família por meio do matrimônio, o que torna "grande parte destas famílias uma mesma grande família" (p. 43), levando a que os principais interesses se conjuguem na finança, sem esquecer seu relacionamento com os governantes políticos que se "instalam" em conselhos de administração de empresas pertencentes a essas famílias.

No capítulo I, "Antecedentes do Estado que faz e desfaz fortunas (1850-1910)", os autores descortinam os fatores e as condiçóes que favoreceram a formação das principais fortunas e re-

* Doutora em estudos africanos pelo Instituto Universitário de Lisboa (ISCTE-IUL), pesquisadora visitante no International Institute of Social History (ISST), Amsterdã. Luanda, Angola. E-mail: ermelinda.liberato@gmail.com. 
des de poder desde a segunda metade do século XIX até a implantação da República em 1910. Os autores identificam seus protagonistas bem como suas fontes de acumulaçáo, dando como exemplos o caso da família de Henry Burnay, "o senhor Milhão" (p. 21), os Ulrich, os Bensaude, entre outros. Data também deste período o surgimento de grandes fortunas que todos os portugueses conhecem na atualidade: Banco Totta, Banco Espírito Santo, Sotto Mayor ou Burnay são apenas alguns dos exemplos referidos. Os autores fazem ainda referência aos capitais coloniais e aos negócios do Brasil, à sua importância no enriquecimento destas famílias, bem como à promiscuidade entre o poder político e as grandes redes econômicas. Em termos econômicos e da história econômica de Portugal, é um período em que o "tabaco e alfândegas eram as fontes de sustento do Estado" (p. 20), e foi em torno desses dois setores que se desenrolaram as principais relaçóes políticas e econômicas, bem como foi em torno dos mesmos que o poder econômico se fortaleceu, pois "em Portugal era sobretudo nos contratos com o Estado que se ganhava dinheiro" (p. 20). Quando a República é implantada em 1910, Portugal apresenta uma arquitetura capitalista "montada sobre um núcleo restrito de famílias que controla a banca, gere as companhias ligadas a setores estratégicos da economia e com enorme dependência do Estado, casa entre si e revela um intenso apetite pela política” (p. 43).

Num período de 35 anos, que decorre desde a implantação de República em 1910 até ao final da Segunda Grande Guerra, Portugal enfrenta novos desafios e vivencia três períodos políticos distintos: queda da monarquia e implantação de um regime republicano (1910-1926), Ditadura Militar (1926-1930) e implantação do Estado Novo (1930 em diante). Assiste-se, ainda, à instalação de uma "nova política imperial, nacionalista e centralizadora, adotada pela Ditadura Militar e depois pelo Estado Novo, a partir de 1926" (p. 149), que tinha como objetivo principal a consolidação do "terceiro Império" (africano). Essa instabilidade política reflete-se na economia que continua atrasada e periférica em relaçáo aos outros países europeus, as- sim como na continuidade do modelo burguês de "Acumular sem modernizar" (capítulo II), incapaz de "democratizar a modernização do país" (p. 16). Durante esse período, a oligarquia portuguesa continuou a ser um "clube restrito e fortemente endogâmico" (p. 50), constituída por uma "rede complexa e diversificada de interesses" (p. 50).

Este debate tem continuidade no capítulo III, em que os autores analisam minuciosamente os atrasos do progresso do país e que levaram a uma decadência em todos os níveis, bem como as tentativas de Portugal se estabelecer em suas possessóes africanas com o intuito de as transformar num "novo Brasil". No que toca à economia e à história econômica portuguesa, esse período fica ainda marcado pela aprovação do código laboral (1899) que "impôs o trabalho forçado aos nativos africanos" (p. 182), bem como pela "parasitagem do capital comercial e financeiro (que) roeu as possibilidades de desenvolvimento econômico" (p. 199). De referir que "quase todas as grandes famílias, nessa época, mantêm um pé bem assente na exploração colonial" (p. 50). O debate sobre o atraso e a decadência de Portugal tem continuidade com os escritos de autores que pertenceram à chamada Geração de 70, a geração dos "vencidos da Vida", da qual fizeram parte grandes nomes da literatura portuguesa como Eça de Queirós, Ramalho Ortigão, Teófilo Braga, Oliveira Martins, Antero de Quental, que, utilizando a escrita, tentaram denunciar o mal-estar social que se registava.

No capítulo IV, "A modernização conservadora (1945-1974)", os autores caracterizam um dos períodos mais controversos da história portuguesa, pois, se por um lado verifica-se, em termos econômicos, um intenso crescimento industrial, por outro verifica-se uma elevada taxa de imigração, sobretudo de jovens que tentavam escapar ao desemprego e à guerra colonial. Em termos econômicos, os territórios ultramarinos transformam-se num "centro de poder para os grupos financeiros e industriais que obtinham matérias-primas baratas" (p. 221). Esse "atraso", apontado como uma das causas para o atual estado econômico em que Portugal se encontra, foi a principal marca da ditadura salazarista/marcelista e dos capitalistas 
portugueses que a ditadura protegia. Tanto assim era que, "nas vésperas do 25 de Abril de 1974, a economia era dominada por este Estado onipotente e por 44 famílias” (p. 239).

Ao tentar fazer uma "interpretação sociológica da história” (p. 253), António Sérgio "formulou uma teoria explicativa para o desenvolvimento do país, para os seus fracassos e atraso" (p. 253), tal como já havia sucedido com a Geração de 70 . Equivocado ou não sobre os modos de modernização da economia portuguesa, António Sérgio acabou concluindo que "a nossa fatalidade é a nossa história” (p. 264), ou seja, o problema maior de Portugal reside em sua história, pois os "atrasos a vencer situam-se nas relaçóes sociais, na ordem da propriedade concentrada" (p. 264).

No último capítulo da obra, "A recomposição da burguesia (1974-2010)", é traçado um retrato de Portugal e de sua burguesia no período que se segue à queda da ditadura e à instauração de um estado democrático até os dias de hoje. Acontecimentos como a integração europeia e as grandes transformaçóes na sociedade portuguesa, a abertura do país a uma economia liberal, as nacionalizaçóes e posteriormente as privatizaçôes, bem como a situação econômica atual de Portugal e a continuidade das relaçóes entre o poder político e as elites econômicas foram igualmente analisados.

Com o fim do regime ditatorial em 1974, Portugal apresenta-se como um país "atrasado, que tem o menor rendimento por habitante da Europa do euro atual, a maior taxa de analfabetismo, a pior cobertura do sistema de saúde ou de segurança social e a maior concentração da população na agricultura” (p. 265). Portugal começa assim sua longa caminhada no sentido de construção de uma sociedade democrática e economicamente liberal, onde todos os cidadãos tenham acesso aos bens e serviços em igualdade de oportunidades para todos. Tem início um longo processo de nacionalizaçáo da economia que levou a uma perda de poder por parte da elite econômica. No entanto, o que parecia ser o fim de um período marcado pela promiscuidade entre o poder político e a burguesia, teve precisamente o efeito contrário. $\mathrm{O}$ fim da ditadura fez com que essa burguesia se reconstituísse mediante outras formas de concentração de capital, tornando-se ainda mais poderosa do que antes do 25 de Abril de 1974. As privatizaçóes iniciadas no governo de Cavaco Silva em 1985 permitiram que os grandes grupos econômicos do passado se fortalecessem, "enquanto alguns novos grupos começaram a emergir, desenvolvendo-se a partir da indústria e cruzando interesses com a banca, como tinha acontecido no início do século anterior" (p. 270). Os escândalos do Banco Comercial Português (BCP), do Banco Português de Negócios (BPN) e do Banco Privado Português (BPP) são apenas alguns exemplos do seu poder e ganância, bem como do privilégio e favorecimento. "A herança é assim um instrumento de sucesso" (p. 338), utilizada nas relaçóes com o poder político e na qual a classe política continua a se apoiar e a apoiar.

Os autores vão mais longe em sua análise e indicam igualmente a ligação destes grupos econômicos com os grupos econômicos angolanos, cuja referência principal é o nome do presidente daquele país, José Eduardo dos Santos, "um dos maiores investidores privados em Portugal" (p. 311), representado por sua filha Isabel dos Santos.

Para o leitor fica claro que nada mudou nos últimos cem anos, pois "Os Donos de Portugal são os mesmos ao longo deste século" (p. 342), apenas têm "interesses mais diversificados, mais incrustados na captaçáo de recursos do Estado por via das rendas e da extração da vida pública, mais alavancados no sistema político, mais envolventes nos partidos dominantes da governação rotativa destas décadas" (p. 343). A obra revela, ainda, o fracasso desta mesma oligarquia que não se conseguiu modernizar e que continua a se beneficiar do atraso e das rendas extraídas ao Estado, sendo este um dos principais fatores que conduziu Portugal à crise que atualmente atravessa, bem como à dificuldade em sair dela. Por isso se pode compreender que a classe dominante é "o principal problema histórico de Portugal” (p. 344).

O livro presta um importante contributo para o conhecimento da história política e econômica de Portugal e da formaçáo e evolução da burguesia 
portuguesa, do poder econômico de certos grupos financeiros, bem como para a compreensão da promiscuidade entre o poder político e estes mesmos grupos econômicos ao longo dos tempos. A obra permite ainda pistas para investigaçóes futuras, que se alargam além-fronteiras, como é o caso de Angola. $\mathrm{O}$ manuseio da abundante infor- mação e a solidez da argumentação presente na obra demonstram a complexidade do tema, pelo que não pode ser lida de um "sopro". Para professores, estudantes, investigadores e público em geral, Os donos de Portugal apresenta-se como uma referência imprescindível e uma obra essencial de consulta. 